\title{
Slow slip on the northern Hikurangi subduction interface, New Zealand
}

\author{
A. Douglas, ${ }^{1}$ J. Beavan, ${ }^{2}$ L. Wallace, ${ }^{2}$ and J. Townend ${ }^{1}$ \\ Received 29 May 2005; revised 14 July 2005; accepted 27 July 2005; published 18 August 2005.
}

[1] In October 2002, a surface displacement episode of 20-30 mm magnitude was observed over a $\sim 10$ day period on two continuous Global Positioning System (GPS) instruments near Gisborne, North Island, New Zealand. We interpret this to result from slow slip on the northern Hikurangi subduction interface. Using ten years of regional campaign GPS (1995-2004) and recent continuous GPS data, we estimate the recurrence interval for similar events to be $2-3$ yrs. In November 2004, a similar slow slip event occurred within this recurrence period. The 2002 event can be modeled by $\sim 18 \mathrm{~cm}$ of slow slip near the down-dip end of the seismogenic zone on the subduction interface offshore of Gisborne. The campaign GPS data show that the 2002 slow slip event had little effect on regional strain patterns. Citation: Douglas, A., J. Beavan, L. Wallace, and J. Townend (2005), Slow slip on the northern Hikurangi subduction interface, New Zealand, Geophys. Res. Lett., 32, L16305, doi:10.1029/2005GL023607.

\section{Introduction}

[2] Transient fault slip episodes, occurring over much longer time periods (days-months) than earthquakes, have been recorded with Global Positioning System (GPS) instruments at several subduction margins [e.g., Dragert et al., 2001; Obara et al., 2004; Larson et al., 2004]. These so-called slow slip events may make a significant contribution to moment release in subduction zones; quantifying their size is therefore a key task in characterizing seismic hazard at subduction zones.

[3] The Raukumara Peninsula, the easternmost part of New Zealand's North Island, is an important location for observations of the northern Hikurangi subduction margin (Figures 1a and 1b). Offshore to the east, the Hikurangi Trough marks the present-day plate boundary where the Pacific plate subducts beneath the North Island. The majority of earthquakes beneath the peninsula occur in a westward-dipping zone defining the down-going Pacific plate [Ansell and Bannister, 1996]. To the west, back-arc extension forms the Taupo Volcanic Zone (TVZ) [e.g., Wilson et al., 1995], separated from the Raukumara Peninsula by the North Island Dextral Fault Belt (NIDFB) (Figure 1b) [Beanland and Haines, 1998].

\footnotetext{
${ }^{1}$ School of Earth Sciences, Victoria University of Wellington, Wellington, New Zealand.

${ }^{2}$ Institute of Geological and Nuclear Sciences, Lower Hutt, New Zealand.
}

Copyright 2005 by the American Geophysical Union. 0094-8276/05/2005GL023607
[4] In October 2002, a rapid (compared to normal plate motion) surface deformation event of $20-30 \mathrm{~mm}$ magnitude was observed over an $\sim 10$ day period on two continuous GPS (CGPS) instruments near Gisborne (GIS1 and GISB; Figure 1c). The event, interpreted as the result of slow slip on the Hikurangi subduction interface by Beavan et al. [2003], occurred during the early stages of CGPS network development in the region. The spatially limited CGPS observations do not constrain the margin-parallel extent of this event. Campaign GPS data from the Raukumara Peninsula may allow better spatial control of the 2002 event and detection of earlier deformation episodes, if the spatial and temporal sampling of the campaign GPS are sufficient [e.g., Larson et al., 2004].

\section{Data}

\subsection{Campaign GPS Data Analysis}

[5] We analyzed GPS data from surveys conducted on the Raukumara Peninsula in January 1995 [Árnadóttir et al., 1999], February 1997 and January 2001, plus a new campaign we conducted in March 2004. To ensure consistency between the results, we used identical processing techniques for all data sets.

[6] In each campaign, data lengths of 24 hours or more were obtained at most sites. The GPS phase data were processed using standard methods and Bernese 4.2 software [Beutler et al., 2001] to determine daily estimates of relative coordinates and their covariance matrices. International GPS Service (IGS) final ITRF2000 orbits and associated polar motion files were held fixed and one station's coordinates (AUCK; Figure 1a) were tightly constrained during each day's processing. AUCK was not installed at the time of the 1995 campaign so we used a tie from a nearby $(375 \mathrm{~m})$ site. All daily coordinate-difference solutions and their covariances were input into least squares software ADJCOORD [Crook, 1992] to check for outliers and construct station position time series. At this stage, stations with very short observing sessions (some 1995 sessions were as short as $4-5$ hours), or with site velocities grossly inconsistent with neighboring sites, were removed from the solutions (less than $5 \%$ of sites).

\subsection{GPS Time Series}

[7] Figure 2a shows station position time series relative to AUCK on the stable Australian plate. The east component of the GISB time series from 2002 to 2005 (Figure 2b) reveals three rapid surface displacement episodes; the first and third were similar in size $(\sim 20-30 \mathrm{~mm})$, while the second was a factor of five smaller and of longer duration. The slow slip event displacements are in an ESE direction, opposite to the WNW direction of subduction of the Pacific 

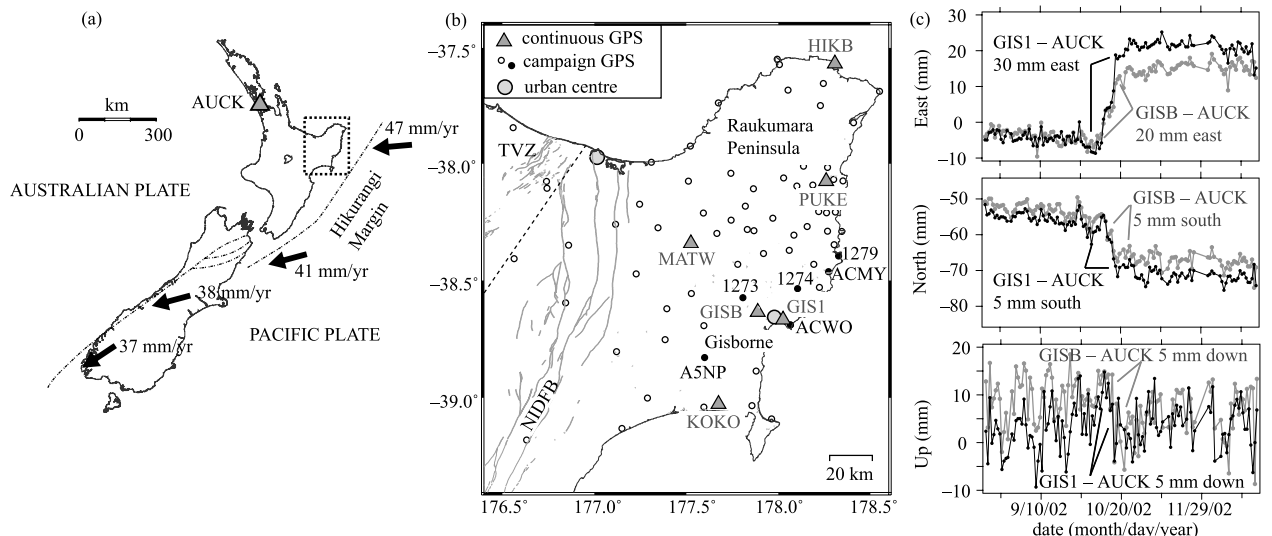

Figure 1. (a) Map showing study area and Pacific-Australia relative velocity vectors [DeMets et al., 1994]. (b) Current Raukumara Peninsula continuous and campaign GPS stations. TVZ - Taupo Volcanic Zone, NIDFB — North Island Dextral Fault Belt. Time series from six campaign sites (solid circles) are shown in Figure 2a. The 2002 slow slip event (c) was recorded on CGPS stations GIS1 and GISB, installed in August 2001 and July 2002 respectively; the other CGPS stations were installed after 2003.

plate beneath the Raukumara Peninsula [Wallace et al., 2004].

\section{Results}

3.1. Constraining the 2002 Event With Campaign GPS

[8] We find that the several-year time intervals between GPS campaigns on the Raukumara Peninsula make it impossible to identify transient motion from the 2002 slow slip event, or any previous slow slip events, in the campaign time series (Figure 2a). The shortest interval between GPS campaign measurements has been 2 years, while it took approximately 1.5 years for the eastward displacement caused by the 2002 event at GISB to be recovered by westward motion at that site. We therefore cannot use the campaign time series to help constrain the spatial extent or moment release of the 2002 slow slip event. However, we can use the campaign data to estimate slow slip recurrence intervals.

\subsection{Slow Slip Recurrence Intervals}

[9] Quasi-periodic recurrence intervals have been observed for slow slip events in the Cascadia subduction margin [e.g., Rogers and Dragert, 2003; Szeliga et al., 2004], and the Guerrero region of Mexico [Lowry et al., 2005]. Recurrence intervals have been used successfully in Cascadia to predict the timing of future events.

[10] To estimate a recurrence interval for slow slip events similar to the Gisborne 2002 event, we compare the "longterm' rates averaged over the ten year span of the campaign time series, with the short-term rates between slip events. This short-term rate is estimated by averaging the best fit linear trends of the CGPS time series during times when no slow slip is taking place. We choose pairs of neighboring stations ACW0 (campaign) and GIS1 ( $\sim 5 \mathrm{~km}$ apart), and 1273 (campaign) and GISB ( $\sim 10 \mathrm{~km}$ apart), which are likely to have similar displacement histories (Figure 2a). As stations 1273 and GISB are further apart we have less confidence in this comparison.

[11] We estimate the average rate at GIS1 between the 2002 and 2004 events to be $18.3 \pm 1.9 \mathrm{~mm} / \mathrm{yr}$ west relative to AUCK. Based on a long-term rate (1995-2004) at ACW0 of $8.7 \pm 0.7 \mathrm{~mm} / \mathrm{yr}$ west, the deficit in westward motion at ACW0 is $9.6 \pm 2.0 \mathrm{~mm} / \mathrm{yr}$. We assume the deficit is due to episodic slow slip events. The 2002 event resulted in $\sim 30 \mathrm{~mm}$ eastward displacement at GIS1, implying a recurrence interval of $\sim 3.1 \pm 0.6$ yrs, assuming the 2002 event has typical surface displacement. Comparing stations 1273 and GISB, we find a deficit in westward motion of $10.9 \pm 1.2 \mathrm{~mm} / \mathrm{yr}$. The 2002 event resulted in $\sim 20 \mathrm{~mm}$ eastward displacement at GISB, giving a recurrence interval
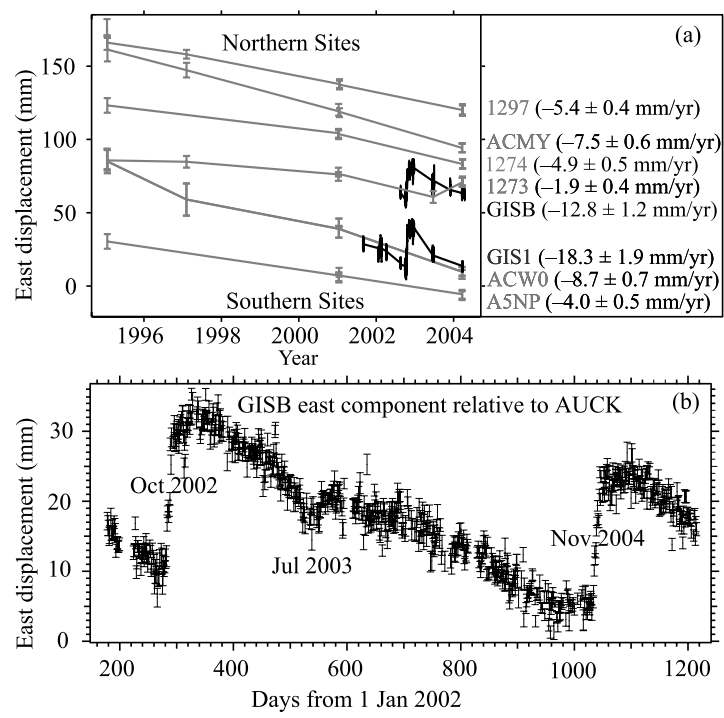

Figure 2. (a) Position time series and velocities relative to AUCK averaged over 1995-2004 interval for selected campaign sites (Figure 1b), and averaged over selected days for CGPS stations GIS1 and GISB. Rates for GIS1 and GISB are estimated by averaging the best fit linear trends during periods when no slow slip is taking place. (b) GISB time series from 2002-2005 showing eastward surface displacements of $20-25 \mathrm{~mm}$ in October 2002 and November 2004, and $5 \mathrm{~mm}$ in July 2003. See color version of this figure in the HTML. 

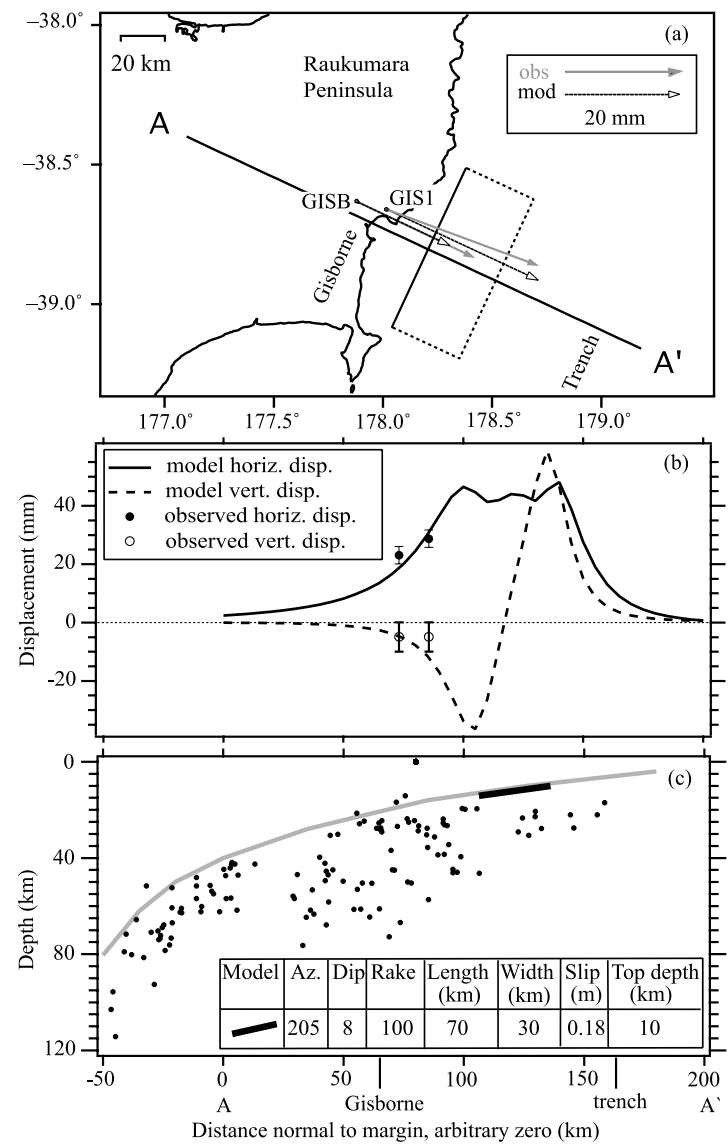

Figure 3. (a) Model slip plane and observed and predicted displacements for 2002 event. Dashed edges of slip plane are not well constrained. (b) Observed and predicted displacements along $\mathrm{A}-\mathrm{A}^{\prime}$. (c) Profile along $\mathrm{A}-\mathrm{A}^{\prime}$ showing model slip plane, current seismicity and subduction interface.

of $\sim 1.8 \pm 0.2 \mathrm{yrs}$. The uncertainties in these recurrence estimates are probably underestimated as we have not incorporated the uncertainty in magnitude of the slow slip events.

[12] Our estimates point to slow slip events similar to the October 2002 event occurring every 2-3 years. In November 2004, an event (Figure 2b) of similar surface displacement was recorded. The timing of this event, $\sim 2.1$ years after the previous one, is consistent with our predicted recurrence interval. Smaller events, such as that in July 2003 (Figure 2b), may modulate the recurrence interval. Though three more continuous GPS stations had been installed in the Raukumara region by November 2004, they were either too far away or too recently installed to provide data to constrain that event.

\subsection{Forward Modeling of the Gisborne 2002 Slow Slip Event}

[13] We interpret the observed displacements for the 2002 slow slip event at GIS1 and GISB using an elastic dislocation model comprising uniform slip on a plane in an elastic half space (Figure 3). The campaign displacements do not provide useful data for this modeling, as discussed above.

[14] We model slip on different parts of the subduction interface by varying the dip, depth and position of the slip plane in accord with the interface geometry inferred from seismology [Reyners, 1998] (Figure 3c). We vary the rake, width and slip by trial and error for each different slip plane location.

[15] One plausible model requires $\sim 18 \mathrm{~cm}$ of thrust slip on a plane whose lower edge is at depth $\sim 14 \mathrm{~km}$ on the subduction interface $\sim 20 \mathrm{~km}$ east of Gisborne (Figure 3a). This model fits the observed horizontal data quite well (Figure $3 \mathrm{~b}$ ) and the downward displacement of the Gisborne CGPS sites. The slip magnitude and lower edge of the event are reasonably well constrained, but the poor spatial distribution of GPS data prevents us constraining its up-dip or lateral extent. We rule out slip on the deeper subduction interface (down-dip of GISB) as those models predict uplift for the Gisborne region.

[16] While fault planes smaller than that in Figure 3 can fit the data equally well, the larger slip required, combined with our estimated slow slip recurrence interval of $2-3 \mathrm{yrs}$, implies that the rate of slip in slow events would exceed the long-term rate of convergence between the Pacific plate and the forearc block of $\sim 54 \mathrm{~mm} / \mathrm{yr}$ up-dip [Wallace et al., 2004].

[17] The slip region in the model of Figure 3 is near the downdip end of the seismogenic zone on the subduction interface [Wallace et al., 2004]. This is similar to the location of slow slip events observed in SW Japan and Cascadia [e.g., Dragert et al., 2001; Obara et al., 2004], though the down-dip end of inter-seismic coupling at the north-eastern Hikurangi subduction zone is comparatively shallow [Reyners, 1998; Wallace et al., 2004].

\subsection{Temporal Variation of Strain}

[18] Árnadóttir et al. [1999] studied temporal variations in maximum shear strain rates on the Raukumara Peninsula using triangulation data from 1925 and 1976 and campaign

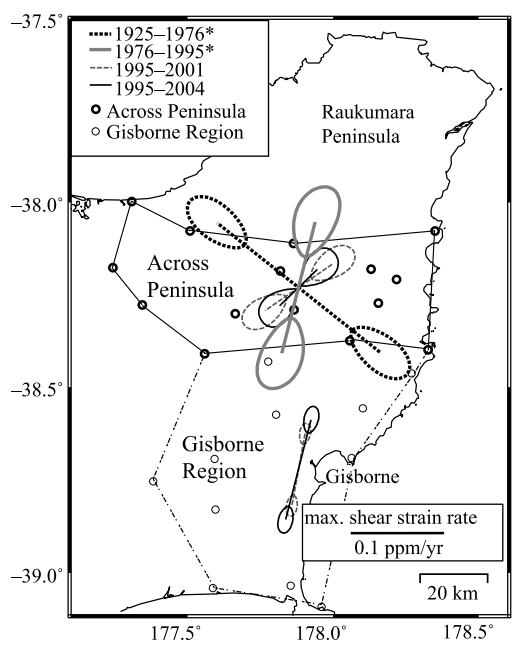

Figure 4. Temporal variation in maximum shear strain rate and azimuth of principal axis of relative extension across the Raukumara Peninsula (from triangulation and GPS between 1925 and 2004;* data from Arnadóttir et al. [1999]), and for the Gisborne region (from 19952004 GPS). Uncertainties are 2-D 68\% confidence regions taking account of random error and the misfit to a uniform strain-rate model. 
GPS from 1995. They interpreted variations in maximum shear strain rate and orientation between the 1925-1976 and 1976-95 epochs to result from aseismic slip over the entire shallow subduction interface to $30 \mathrm{~km}$ depth between the 1920s and 1970s. To investigate strain rates since 1995, we calculate the magnitude of the maximum shear strain rate and the orientation of the principal extension axis over the Raukumara Peninsula using all available campaign GPS data (Figure 4). Our strain calculation regions are based on those of Arnadóttir et al. [1999].

[19] Figure 4 shows there was no significant change in shear strain rate either across the Raukumara Peninsula or in the Gisborne region between 2001 and 2004, over a period when slow slip events are known to displace CGPS sites in the Gisborne region. For the 'Across Peninsula' region, there is a small but not statistically significant clockwise rotation of the 1995-2001 and 1995-2004 strain-rate azimuths as compared to 1976-1995. However, these three directions all differ significantly from the 1925-1976 direction (Figure 4).

[20] The slip on the subduction interface modeled by Árnadóttir et al. [1999] to explain temporal variation in strain between 1925-1976 and 1976-1995 was of wide lateral extent and reached to $30 \mathrm{~km}$ depth. It is very different in character to the Gisborne slow slip events recorded in 2002-2004. In our model for the 2002 event, the subduction interface slips to a depth of only $\sim 15 \mathrm{~km}$, and the slipping region may be localised near the bottom of the seismogenic zone.

\section{Conclusions}

[21] Low temporal sampling in station position time series from the Raukumara Peninsula campaign GPS data set aliases the Gisborne 2002 slow slip event, seen as 20$30 \mathrm{~mm}$ of surface displacement at CGPS sites in the region. While we cannot use the campaign GPS data to constrain the spatial extent of the 2002 event, we can estimate that such events may recur at 2-3 year intervals, compatible with the timing of the November 2004 event.

[22] Elastic dislocation models show the 2002 event to be consistent with slip on the subduction interface offshore of Gisborne. We cannot accurately constrain the north-south or up-dip extents of the modeled slip plane, but we find that the down-dip extent is consistent with slip occurring near the down-dip limit of the seismogenic zone.

[23] We find that the 2002 event did not have a significant effect on regional strain-rate patterns over the Raukumara Peninsula.
[24] Acknowledgments. Funding from the Earthquake Commission (AD and JT) and the Foundation for Research, Science and Technology (JB and LW) is gratefully acknowledged. GISB data are from the GeoNet data centre (http://www.geonet.org.nz). GIS1 is operated by Ian Bell, Bell Resources, Gisborne. The manuscript benefited from the reviews of Thora Árnadóttir and an anonymous reviewer.

\section{References}

Ansell, J., and B. Bannister (1996), Shallow morphology of the subducted Pacific plate along the Hikurangi margin, New Zealand, Phys. Earth Planet. Inter., 93, 3-20.

Árnadóttir, T., S. Thornley, F. Pollitz, and D. Darby (1999), Spatial and temporal strain rate variations at the northern Hikurangi margin, New Zealand, J. Geophys. Res., 104, 4931-4944.

Beanland, S., and J. Haines (1998), The kinematics of active deformation in the North Island, New Zealand, determined from geological strain rates, N. Z. J. Geol. Geophys., 41, 311-323.

Beavan, J., L. Wallace, and T. Hurst (2003), Observation of an aseismic deformation episode above the northern Hikurangi Margin subduction zone, New Zealand, Geophys. Res. Abstr., 5, abstract EAE03-A-04839.

Beutler, G., et al. (2001), Bernese GPS software version 4.2 manual, edited by U. Hugentobler, S. Schaer, and P. Fridez, 418 pp., Astron. Inst., Univ. of Bern, Bern.

Crook, C. (1992), ADJCOORD: A Fortran programme for survey adjustment and deformation modelling, N. Z. Geol. Surv. EDS Rep., 138, $1-22$.

DeMets, C., R. Gordon, D. Argus, and S. Stein (1994), Effects of recent revisions to the geomagnetic reversal time scale on estimates of current plate motions, Geophys. Res. Lett., 21, 2191-2194.

Dragert, H., K. Wang, and T. James (2001), A silent slip event on the deeper Cascadia subduction interface, Science, 292, 1525-1528.

Larson, K., A. Lowry, V. Kostoglodov, W. Hutton, O. Sanchez, K. Hudnut, and G. Suarez (2004), Crustal deformation measurements in Guerrero, Mexico,J. Geophys. Res., 109(B4), B04409, doi:10.1029/ 2003JB002843.

Lowry, A., K. Larson, V. Kostoglodov, and O. Sanchez (2005), The fault slip budget in Guerrero, southern Mexico, Geophys. J. Int., 200, 1-15.

Obara, K., H. Hirose, F. Yamamizu, and K. Kasahara (2004), Episodic slow slip events accompanied by non-volcanic tremors in southwest Japan subduction zone, Geophys. Res. Lett., 31, L23602, doi:10.1029/ 2004GL020848.

Reyners, M. (1998), Plate coupling and the hazard of large subduction thrust earthquakes at the Hikurangi subduction zone, New Zealand, N. Z. J. Geol. Geophys., 41, 343-354.

Rogers, G., and H. Dragert (2003), Episodic tremor and slip on the Cascadia subduction zone: The chatter of silent slip, Science, 300, 1942-1943.

Szeliga, W., T. Melbourne, M. Miller, and M. Santillan (2004), Southern Cascadia episodic slow earthquakes, Geophys. Res. Lett., 31, L16602, doi:10.1029/2004GL020824.

Wallace, L., J. Beavan, R. McCaffrey, and D. Darby (2004), Subduction zone coupling and tectonic block rotations in the North Island, New Zealand, J. Geophys. Res., 109(B12), B12406, doi:10.1029/ 2004JB003241.

Wilson, C., B. Houghton, M. McWilliams, M. Lanphere, S. Weaver, and R. Briggs (1995), Volcanic and structural evolution of Taupo Volcanic Zone, New Zealand: A review, J. Volcanol. Geotherm. Res., 68, 1-28.

J. Beavan and L. Wallace, Institute of Geological and Nuclear Sciences, Lower Hutt, New Zealand.

A. Douglas and J. Townend, School of Earth Sciences, Victoria University of Wellington, Wellington 6001, New Zealand. (annie.douglas@ gmail.com) 